\title{
RECLAMATION OF GASOLINE USED IN DRY CLEANING
}

\author{
By C. C. Hubbard
}

\section{ABSTRACT}

This paper outlines and discusses briefly the processes that have been used in the dry-cleaning industry for the "purification" and recovery of gasoline from the material that has become dirty in use. Results are reported of experimental studies in the laboratory and in dry-cleaning plants and of largescale tests in dry-cleaning plants, using activated carbon and an aqueous solution of trisodium phosphate. A process is recommended for the rapid and economical purification and recovery of gasoline in large or small plants. The salient features of this process are treatment of the solvent with activated carbon and an aqueous solution of trisodium phosphate, definite time of agitation, definite temperature range, settling, and finally decantation of the colorless, recovered solvent. The process also provides for the recovery of the gasoline retained by the sludge.

\section{CONTENTS}

I. Introduction

II. Processes of reclamation _ 142

1. Distillation process_-_- 142

2. Centrifugal process_-_. 143

3. Simple filtration process _-_- 143

4. Carbon process

5. Acid process _._._- 143

6. Caustic alkali-centrifugal process______- 143

7. "Titration" process__-__- 143

8. Caustic alkali-filtration process _- 143

9. Acid-alkali process _-____- 144

10. Carbon-phosphate process___- 144

III. Experimental studies in the laboratory

IV. Experimental studies in dry-cleaning plants__________-_._-_ 145

V. Plant tests with special equipment_-_. 146

VI. Conclusions from laboratory and plant tests_____-_ 148

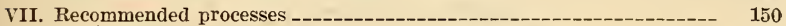

1. Large-scale plants without centrifugal clarifier_________ $\quad \mathbf{1 5 0}$

(a) Materials _. 150

(b) Equipment__- 150

(c) Procedure_-_-_-_-_- 150

2. Large-scale plants with centrifugal clarifier-_-_-_-__-_-_ $\mathbf{1 5 2}$

(a) Equipment _._- 152

(b) Procedure

3. Small-scale plants___- 152

(a) Equipment _._._. 152

(b) Procedure 


\section{INTRODUCTION}

"Dry cleaning," so-called, is performed in a variety of ways, in all of which, however, the garment is immersed in a fluid other than water. It is agitated more or less to loosen and remove as far as possible soiling materials which may be held in the cloth. Soaps soluble in benzine or gasoline are used in conjunction with the drycleaning fluid or solvent. The solvent containing soap in solution becomes discolored and foul and finally unsuited for use in the cleaning process. It is then purified and recovered. The time required for the solvent to become too foul for use depends upon a number of factors, such as the nature of the soiling materials encountered, the number of garments cleaned, the character of the solvent, soap, appliances, etc. The solvent in most general use is ordinary motor gasoline, as sold at the automobile filling stations. The dry-cleaning industry of the United States uses about $45,000,000$ gallons of such gasoline per year. Obviously, a cheap and satisfactory substitute for gasoline or a rapid and economical process for the purification and recovery of used dry-cleaning solvent is of vital interest to this industry as well as the whole country.

In August, 1923, the writer was appointed a research fellow by the National Association of Dyers and Cleaners to work at the Bureau of Standards on the reclamation of used solvent. This paper reports the results of this study and describes a recommended procedure. Acknowledgment is made to L. M. Gill, chemical engineer, New York, N. Y., and to the Sunshine Dry Cleaning \& Dyeing Co., and the Rubenstein Cleaning Co., of Washington, D. C., for advice and assistance in carrying out the plant-scale tests, and to F. W. Smither of the chemistry division, and numerous other members of the staff of the Bureau of Standards.

\section{PROCESSES OF RECLAMATION}

Some of the processes that have been used in the dry-cleaning industry may be outlined as follows:

\section{r. DISTILLATION PROCESS}

In some plants the used solvent is recovered by distillation. This process is in disfavor owing to a loss of the solvent, partly by incomplete condensation but mainly on account of the "heavy ends" in motor gasoline. These "ends" are not "cracked" at the temperature employed and are discharged from the still with the residue of "soil" removed from the garments, together with the soap that was in solution in the solvent. The redistilled gasoline is not as sweet as that purified by the method recommended. Fuel consumption is also an adverse factor. 


\section{CENTRIFUGAL PROCESS}

The centrifugal process is not satisfactory alone because fatty matter remains in solution and causes rancidity. The solvent remains amber colored.

\section{SIMPLE FILTRATION PROCESS}

Filtration by gravity through fuller's earth, sand, or charcoal is unsatisfactory on account of the clogging of the filter, which necessitates frequent renewals and slows down the output.

\section{CARBON PROCESS}

Treatment with activated carbon alone is slow and the effectiveness of the carbon is soon destroyed; however, a water-white product can be obtained.

\section{ACID PROCESS}

Treatment with sulphuric acid alone is not satisfactory as the product causes white woolens to become steel-gray in color, especially when the garments contain a slight excess of moisture over their normal content of hygroscopic moisture.

\section{CAUSTIC ALKALI-CENTRIFUGAL PROCESS}

Fatty matter, including the gasoline-soluble soap used in dry cleaning, is precipitated by adding sodium hydroxide solution to the solvent and the mixture is centrifuged. This process is objectionable on acount of the amber color retaned by the solvent.

\section{7. “TITRATION” PROCESS}

The "titration" process requires the addition of the exact amount of caustic soda, as determined by titration, to the solvent to convert the dry-cleaning soap (a "super-fatted" soap) into "wet-cleaning." or ordinary soap, which does not contain an excess of fatty acids. The wet-cleaning soap is insoluble in the gasoline and precipitates out, carrying dirt or suspended matter with it. This process is in use in some plants but requires careful control, as either an insufficient quantity or an excess of caustic soda will retard, and may prevent, settling. The process is not applicable if the solvent contains appreciable amounts of ammonia.

\section{CAUSTIC ALKALI-FILTRATION PROCESS}

Treatment with caustic soda solution and final filtration up through fuller's earth, sand, or carbon is slow and expensive owing to the necessity of recharging the filter materials at short intervals and the slow speed of production. 


\section{ACID-ALKALI PROCESS}

In the acid-alkali process 100 gallons of the used solvent was mixed with 7.5 pounds of sulphuric acid, agitated, allowed to settle for 12 hours, decanted, and treated with 10.5 pounds of a solution of sodium hydroxide, then allowed to settle and decanted for use. This process was discontinued on account of the time required and the danger in handling the materials.

\section{I0. CARBON-PHOSPHATE PROCESS}

The carbon-phosphate process consists in treatment with activated carbon ${ }^{1}$ and an aqueous solution of trisodium phosphate. This is the process which has been found to be most satisfactory and is described in detail in the succeeding pages.

\section{EXPERIMENTAL STUDIES IN THE LABORATORY}

Dirty solvent (gasoline) was obtained from the dry-cleaning plants in Washington, D. C. This material had originally been bought from tank wagons and was the ordinary gasoline sold at automobile filling stations. Preliminary tests with various materials indicated that the activated carbons (hereafter called carbon) would probably be suitable for the purpose. Of nine such carbons tested, one appeared to be the best suited. Mixing the solvent with carbon alone decolorized the solvent, but the settling out of the carbon and any adsorbed matter was very slow. A variation of the percentage of carbon used did not improve this. Agitation by mechanical means or by compressed air caused a more intimate contact of the materials and gave slightly better results. Agitation by means of live steam resulted in emulsification.

The dry-cleaning or benzine soap in solution in the used drycleaning solvent not only holds in suspension the finely divided dirt or soiling matter, but tends to keep the carbon in suspension for a considerable period of time. The dry-cleaning soap apparently acts as a protective colloid and tends to stabilize the suspension.

If caustic-soda solution is added to the dirty solvent, the free fatty acids of the dry-cleaning soap are neutralized and wet-cleaning soap is formed. The latter is insoluble and is therefore precipitated, carrying with it dirt and other suspended matter, including the carbon. This precipitate does not carry down with it all of the (dissolved) coloring matter, unless activated carbon is present. The various substances which are used for neutralizing the fatty acids destroy the protective action of the dry-cleaning soap, and facilitate the flocculation and precipitation of the carbon.

\footnotetext{
1. Activated earbon is carbon which has been treated chemically and otherwise in order to increase its decolorizing power.
} 
Sodium hydroxide, potassium hydroxide, sodium carbonate, sodium silicate, and trisodium phosphate were used in conjunction with carbon in laboratory tests. Of these, trisodium phosphate was the most satisfactory, mainly on account of the more rapid settling of the precipitated and suspended matter. These laboratory tests indicated that trisodium phosphate in aqueous solution has sufficient alkalinity to convert the dry-cleaning soap into wet-cleaning soap. Furthermore, trisodium phosphate can be safely handled and is to be preferred in this respect to the other alkaline substances tested. It was further noted that the carbon, in order to be effective in this process, must be wetted with gasoline or the solvent before it comes in contact with the alkaline aqueous solution. Laboratory tests in which amber-colored used solvent (gasoline) was treated with carbon and trisodium phosphate solution and agitated with compressed air for 5 to 15 minutes showed rapid settling. Within 10 minutes 70 per cent of the gasoline, still slightly cloudy, could be decanted. Within 20 minutes 80 per cent, and within one hour 85 per cent, of a sweet, water-white product could be decanted. On standing overnight 92 per cent recovery was obtained. One charge of carbon and trisodium phosphate can be used for several treatments, depending upon the condition of the gasoline.

\section{EXPERIMENTAL STUDIES IN DRY-CLEANING PLANTS}

Tests were next started on a commercial scale in dry-cleaning plants in Washington, D. C. A cone-bottom, 200-gallon tank was used and agitation was accomplished by means of compressed air from the pumping system in the plant. Dirty, used dry-cleaning solvent, of a very dark amber color and heavily charged with sludge, was selected for treatment. Eleven pounds of trisodium phosphate was dissolved in 12 gallons of water and transferred to the treating tank through a funnel attachment; then 13 pounds of carbon was mixed in gasoline so that the mixture could be poured through the funnel into the treating tank. Two hundred gallons of the dirty solvent was then pumped from an underground storage tank into the treating tank through a pipe extending to the bottom; then a valve on the suction line of a second, empty, underground storage tank was opened and air forced through the mixture for 15 minutes.

Result: One hundred and sixty-five gallons of a water-white product was siphoned off after one hour of settling. The remainder of the gasoline was absorbed by the purifying agents and sludge that settled out. 
Another lot of 200 gallons of dirty solvent was added to the residue left from the preceding test and agitated 15 minutes.

Result: A water-white product was decanted after one hour of settling.

A third test was run with 200 gallons of solvent and the residue left in the tank from the previous tests.

Result: The rate of precipitation was comparatively slow. After three hours of settling the supernatant solution was clear, but of a light straw color. The total amount of solvent retained by the precipitate after these three tests was about 35 gallons.

Much of the gasoline used in the above tests contained heavy muck which had settled to the bottom of the underground storage system in the plant over a considerable period of time, so it was concluded that the equipment should be cleaned out and tests run on dirty, highly colored solvent, free from excessive muck which causes unduly rapid fouling of the purifying materials.

In this new series of tests 15 pounds of trisodium phosphate was dissolved in 12 gallons of water and transferred to the tank; then 13 pounds of carbon was dumped into the top of the tank while filling it with 200 gallons of the dirty gasoline. The mixture was finally agitated for 15 minutes. After settling for one hour a waterwhite product was siphoned off. Then 10 gallons of muck was drawn off at the top of the cone, 200 gallons of dirty solvent pumped into the tank, and the mixture agitated as before. After settling one hour a water-white product was siphoned off to the underground storage system.

In each successive treatment 10 gallons of muck was drawn off before refilling the tank with dirty solvent, at the rate of three tankfuls a day for about four days, using the initial charge of phosphate and carbon throughout. About 1,000 gallons of a water-white product was obtained and then at the eleventh refilling with solvent a light, straw-colored product was obtained. The purifying agents then showed signs of fouling. In this series of tests 2,200 gallons of the solvent was purified by the one charge of phosphate and carbon.

From the experience gained in the above tests it was decided to construct equipment for agitating and also for handling the phosphate solution and carbon.

\section{PLANT TESTS WITH SPECIAL EQUIPMENT}

The next series of tests was made on used dry-cleaning solvent from which the sediment had been removed during the "continuous process" ${ }^{2}$ by means of a DeLaval centrifugal clarifier.

2 In this process the gasoline runs from the bottom of the dry-cleaning machine to a clarifier to remove the heavier sediment and then back to the dry-cleaning machine during the process of cleaning. 
The equipment consisted of two 250-gallon cone-bottom tanks, equipped with a floating pipe drainage system. The tanks were connected in tandem with one $11 / 2$-inch Gould centrifugal pump. One mixing hopper was connected to the pump for injecting the purifying agents. One Merten's leaf pressure-filter of the Danek type was installed for filtration.

In the first run 230 gallons of the dirty gasoline was pumped into one of the treating tanks, 13 pounds of carbon was mixed with gasoline in the mixing hopper above the centrifugal pump and pumped into the treating tank; then 15 pounds of trisodium phosphate was dissolved in 12 gallons of water and pumped into the tank containing the solvent and carbon. The mixture was then agitated with the centrifugal pump by pumping the mixture from the bottom tip of the cone and discharging it back through pipe connections, upward through the center of the tank, for a period of 15 minutes.

Results: After settling for 15 minutes, 192 gallons of water-white gasoline was decanted through the floating drain line and pumped through the filter under 5 pounds pressure. Filtration required one hour. The sludge in the bottom of the tank occupied less than one-half of the cone.

In the second run 180 gallons of dirty gasoline was pumped into the treating tank upon the residue left from the first run and the mixture was agitated for 32 minutes.

Result: An emulsion was formed that required distillation to recover the gasoline, as the filter would not handle water.

As a result of this experience tests were run to fix the limits of the time of agitation required. It was found that a $1 \frac{1}{2}$-inch centrifugal pump (50 gallons per minute capacity) acts so vigorously that agitation for more than 20 minutes resulted in the formation of an emulsion that required 72 hours to settle out. With the centrifugal pump the best results were obtained with an agitation period of 10 to 15 minutes.

Agitation by means of compressed air or a plunger-type pump for an extended period did not produce an emulsion; however, $15 \mathrm{~min}-$ utes is sufficient for all types of equipment.

Tests were also made to determine the range of temperature for successful operation. At temperatures below $10^{\circ}$ C. $\left(50^{\circ} \mathrm{F}\right.$.) the trisodium phosphate crystallizes out from solutions of the concentrations used, and it ceases to act until it is redissolved by raising the temperature. A superheater on the solvent-feed line is, therefore, suggested for winter operation in districts in which the temperature of the solvent to be treated falls below $10^{\circ} \mathrm{C}$. $\left(50^{\circ} \mathrm{F}\right.$.). At temperatures above $32^{\circ} \mathrm{C}$. $\left(90^{\circ} \mathrm{F}\right.$.) the insoluble matter settles out very slowly from the solvent that is being treated. 
Starting with clean equipment, the following tests were run: $(a)$ Two hundred and thirty gallons of dirty solvent was pumped into the treating tank, 18 pounds of carbon mixed with gasoline was run in from the hopper, and then 5 pounds of trisodium phosphate dissolved in 12 gallons of water. The mixture was agitated for 15 minutes with the centrifugal pump. After settling 15 minutes, 200 gallons of water-white gasoline was decanted by gravity to the underground system.

(b) Two hundred gallons of dirty gasoline was pumped in on the residue remaining in the tank from $(a)$, and the mixture agitated for 15 minutes. After settling 30 minutes, 200 gallons of water-white gasoline was decanted by gravity to the underground storage tank.

(c) Two hundred gallons of dirty gasoline was pumped into the treating tank upon the residue from $(b)$, and the mixture agitated 15 minutes. After settling 15 minutes, 200 gallons of water-white gasoline was decanted by gravity to the underground system.

(d) Two hundred gallons of dirty gasoline was pumped into the treating tank upon the residue from $(c)$, and the mixture agitated for 15 minutes. The insoluble and precipitable matter settled out very slowly. After 30 minutes of settling, a sample of the mixture was tested for alkalinity. The test indicated insufficient trisodium phosphate, only 5 pounds of which was added at the start. Then 2 pounds of phosphate dissolved in 3 gallons of water was pumped in and the mixture agitated for 10 minutes. An emulsion resulted from overagitation (25 minutes). The test also indicated that it may be best to add the trisodium phosphate in one lot and not portion wise.

After cleaning the equipment, a number of successful runs were made with a charge of 15 pounds of carbon and 15 poundis of trisodium phosphate dissolved in 15 gallons of water.

The sludge from the treating tank, after treating 5 to 10 successive lots of solvent, contains all of the "loss" of solvent, amounting to about 30 gallons. This sludge may be drawn off and stored in a barrel or tank built for the purpose. By adding an equal volume of water to this sludge and allowing the mixture to settle for 24 hours, practically all of the retained gasoline can be decanted off as a water-white product.

\section{CONCLUSIONS FROM LABORATORY AND PLANT TESTS}

Agitation is necessary to bring about intimate contact of the solvent and the purifying agents. Agitation with a Bowser plungertype pump, delivering about 15 gallons per minute, for 30 minutes or vigorous agitation with compressed air for 30 minutes did not 
cause emulsification. When a $1 \frac{1}{2}$-inch centrifugal pump throwing 50 gallons per minute is used, the time of agitation should not exceed 10 to 15 minutes.

The amount of sludge deposited with the carbon and trisodium phosphate solution in the bottom of the treating tank is insignificant where the "continuous process" of clarification is used in drycleaning processes, as the impurities remaining in the gasoline are mainly coloring matter and soap.

The temperature of the mixture undergoing treatment should not be below $10^{\circ} \mathrm{C}$. $\left(50^{\circ} \mathrm{F}\right.$.) or above $32^{\circ} \mathrm{C}$. $\left(90^{\circ} \mathrm{F}\right.$.).

Purification of new stock supplies of gasoline to remove color and disagreeable odor is recommended. This can be satisfactorily accomplished with a charge of purifying agents that has been repeatedly used with dirty solvent.

The process is applicable to solvents containing large or small amounts of soiling materials, but with the former the purifying agents foul more quickly.

After the total supply of gasoline in storage has been purified to a water-white color, the demand for purification, to keep the cleaning solvent in good condition, becomes less, and purification by this process may not be required any more often than distillation was formerly resorted to.

The cost of purifying the used gasoline to a water-white color depends on the amount and nature of the "soil " or other impurities it contains. For example, a retail cleaning plant handling no greasy overalls reports 6,700 gallons of used cleaning solvent purified to a water-white color for $\$ 1.75$. A wholesale plant reports 2,200 gallons of dirty used solvent purified to a water-white color for $\$ 3$. An overall cleaning plant reports 1,000 gallons of dirty solvent purified to a water-white color for $\$ 3.25$.

Experiments indicated that trisodium phosphate in aqueous solution was the most satisfactory of the alkaline materials tested for flocculating and precipitating the carbon.

An excessive amount of carbon is not detrimental. However, equal weights of carbon and trisodium phosphate seem to become spent simultaneously. The carbon must be wetted with gasoline before coming in contact with water.

No float device to "skim" the top of the settled solvent is necessary, for when the solvent is settled properly it is as clear just above the precipitated layer as it is at the top of the tank and may be drawn off by gravity.

The process is flexible and simple enough to be applied in any plant, large or small. Estimates of tankage requirements are:

For a $\$ 300,000$ volume of business per year: Two 500-gallon conebottom tanks and one 11/2-inch centrifugal pump. 
For a business of $\$ 50,000$ to $\$ 200,000$ per year: Two 250-gallon cone-bottom tanks and one $11 / 2$-inch centrifugal pump.

For a business of less than $\$ 50,000$ per year: One 250 -gallon conebottom tank and one 11/2-inch centrifugal pump.

Most establishments would probably need to make little or no change of equipment to use the process. Practically all of the gasoline held by the sludge from the treating tanks can be recovered. The treating tanks can be quickly cleaned with water after the sludge is run out. The process does not conflict with or pertain to the "continuous process" common to the industry, but is considered as replacing the process of distillation.

\section{RECOMMENDED PROCESSES}

The following processes make it possible for the small or large establishment, wherever located, to obtain gasoline and purify it to an odorless and sweet water-white product that may be used on white and all other classes of garments.

\section{r. LARGE-SCALE PLANTS WITHOUT CENTRIFUGAL CLARIFIER}

(a) Materials.-The purifying agents consist of carbon and trisodium phosphate.

(b) Equipment.-The equipment consists of a 200 to 250 gallon cone-bottom tank, a 11/2-inch centrifugal pump, a superheater, a thermometer, a gravity drainage line, and a mixing vessel on a platform (see fig. 1).

(c) Prockdure:-(1) Place the container (50 pounds) of carbon on the platform level with the top of the mixing vessel.

(2) Pour 10 gallons of gasoline into the mixing vessel.

(3) With a scoop (a 1-pound sugar scoop) put 13 scoopfuls (about $61 / 2$ pounds) of carbon into the gasoline in the vessel.

(4) Stir the gasoline and carbon until the mixture is of a smooth consistency, and then pump into the 200 to 250 gallon tank.

(5) Again place 10 gallons of gasoline in the mixing vessel, add 13 scoopfuls of carbon, mix, and pump into the tank as before.

(6) Place 12 scoopfuls (1-pound scoop) of crystallized trisodium phosphate $\left(\mathrm{Na}_{3} \mathrm{PO}_{4} \cdot 12 \mathrm{H}_{2} \mathrm{O}\right)$ in the mixing vessel, add 12 gallons of water, stir until dissolved, and then pump into the 200 to 250 gallon tank. (Hot water may be used to dissolve the phosphate provided it does not raise the temperature of the gasoline being treated above about $26^{\circ} \mathrm{C}$. $\left(80^{\circ} \mathrm{F}\right.$.). During warm weather, water from the city supply line will be satisfactory.)

(7) Pump the dirty, used cleaning solvent (gasoline) into the cone-bottomed tank, containing the carbon and phosphate, until it is nearly full. This may be done at the start, if desired. 
(8) Start the centrifugal pump and open the bottom valve from the pump to the cone. Continue agitation for 15 minutes, then stop the pump.

(9) After allowing 15 minutes for the sludge to settle, drain by gravity the clear, water-white solvent above the sludge to the under. ground storage tank.

A second lot of dirty solvent can be cleaned by simply pumping it in upon the carbon and trisodium phosphate mixture remaining in the tank, agitating for 15 minutes, settling as before, and drawing off above the sludge line. This may be continued with new or old

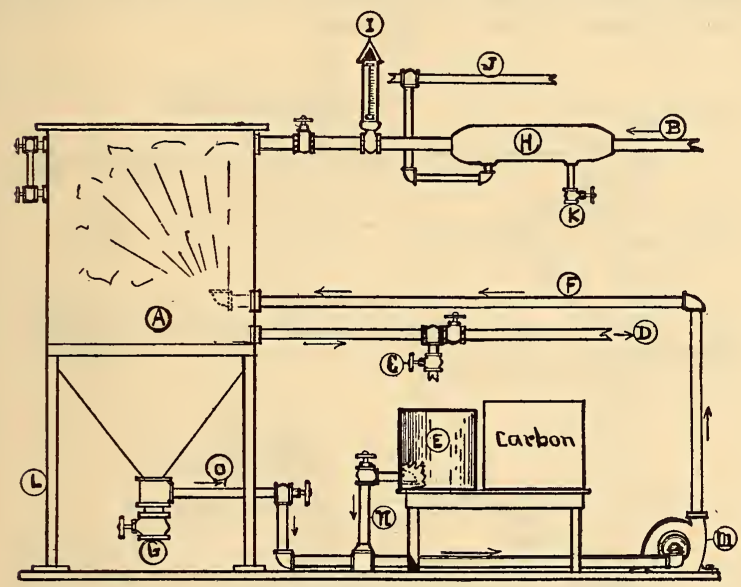

Fig. 1.-Purifying equipment for large-scale plants without centrifugal clarifier

solvent purification. When the purifying agents begin to foul with impurities, they continue to settle out, carrying soap, dirt, etc., but the recovered gasoline has a straw color. Then the sludge should be run off into a tank or other vessel for subsequent recovery of the retained gasoline, the tank washed out with water, and recharged with fresh carbon and trisodium phosphate, as described above.

The superheater (fig. 1) heats by indirect steam the dirty solvent being pumped into the treating tank. The temperature of the solvent should be between 10 and $26^{\circ} \mathrm{C}$. (50 and $80^{\circ} \mathrm{F}$.). This preheating will not be necessary except during the winter months in certain sections. 
2. LARGE-SCALE PLANTS WITH CENTRIFUGAL CLARIFIER

(a) Equipment.-Another adaptation of the process requires a 200 to 250 gallon cone-bottom tank, a $1 \frac{1}{2}$-inch centrifugal pump, a swing float, and a centrifugal clarifier (see fig. 2).

(b) Procedore.-Follow the process as described above, except that after agitation of the mixture in the cone-bottom tank for 15 minutes the time of settling is about 5 minutes. Then drain off, above the sludge line, through a centrifugal clarifier which will remove the small amount of carbon still in suspension and will deliver a clear, water-white product. In this process not enough carbon is removed from the purifying charge to affect the subsequent treatment of more used solvent.

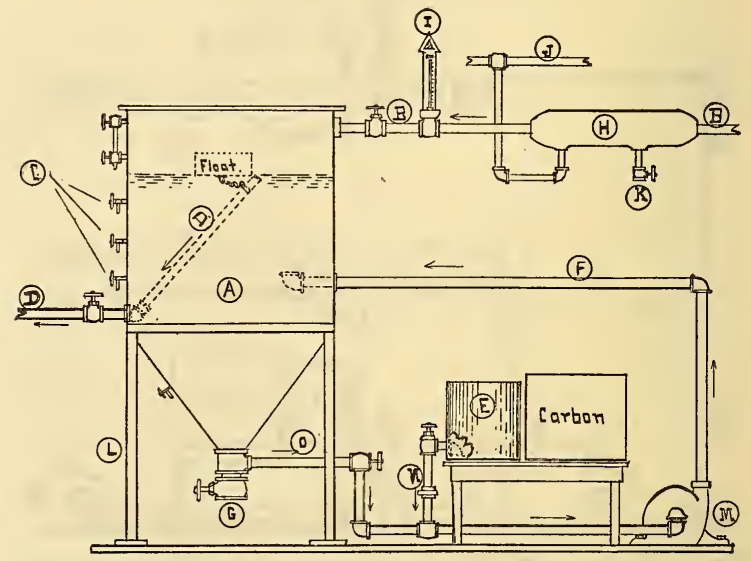

FIG. 2.-Purifying equipment for large-scale plants with centrifugal clarifier

\section{SMALL-SCALE PLANTS}

(a) Equipment.-Figure 3 illustrates another adaptation of the process, using a 100 -gallon treating tank.

(b) Procedure.-(1) Mix 6 pounds of carbon with 8 to 10 gallons of gasoline and pour into the tank through the side funnel.

(2) Dissolve 6 pounds of trisodium phosphate in 6 gallons of water and pour through the funnel. Then close the valve on the funnel.

(3) Pump dirty, used solvent into the tank until it is nearly full. The filling line is provided with a superheater for use when necessary.

(4) Now open a valve on the suction side of the underground system pump to an empty tank and agitate for 15 minutes, either by 
pumping air through the filling line or with compressed air, if the underground system pump can not be spared for the necessary length of time.

(5) Allow the system to stand until the sludge has settled out. This will require from 10 minutes to 1 hour according to the temperature and other conditions.

(6) Test the gasoline from try cocks or at the draw-off line at the top of the cone, and when clear, drain it off by gravity to the underground system.

There are probably many other arrangements whereby equipment on hand may be utilized for the successful operation of the process.

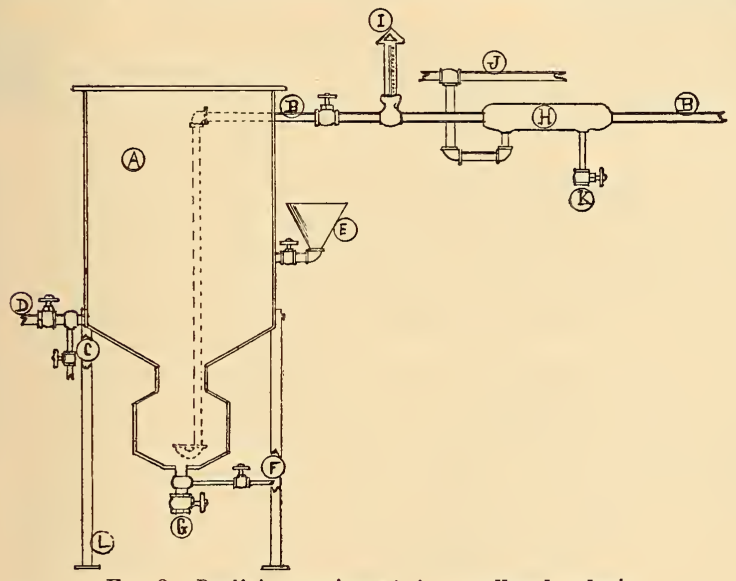

Fig. 3.-Purifying equipment for small-scale plants

The purifying charge, in addition to the impurities, etc., precipitated as a sludge, retains about 30 gallons of gasoline from a 250gallon charge of solvent. This is taken up mainly from the first charge of solvent, as subsequent treatments of solvent with the same charge of purifying agents give practically 100 per cent recovery. When the purifying agents have become fouled, the sludge, or the accumulations of sludge from previous treatments, may be mixed in a tank or other suitable vessel with an equal volume of water, stirred, and allowed to settle 12 to 24 hours. The clear, supernatant gasoline can then be siphoned or decanted off to the underground system.

Washington, October 21, 1924. 